\section{What to write on Mental Health Act form 38}

Sir: It is surprising that there should still be problems between consultants and Mental Health Act Commissioners over what responsible medical officers (RMOs) should write on Mental Health Act form 38 when their detained patients consent to treatment.

Mental Health Act Commissioners have, for many years, expressed the belief that RMOs should write, for medication, the names and dosages of the specific drugs to which the patients had consented. This is not only out of accord with what the Mental Health Act 1983 and its Code of Practice require, it would also unduly restrict our therapeutic interventions, since we would have to fill in a new form 38 each time we altered the dosage of any specific psychotropic drug, or substituted one drug for another of the same class.

Section 58(3) of the Mental Health Act 1983 states that, subject to section 62 of the act, “. . . a patient shall not be given any form of treatment to which this section applies [i. e. treatments requiring consent or a second opinion] unless (a) he has consented to that treatment and either the responsible medical officer or a registered medical practitioner appointed for the purposes of this Part of this Act by the Secretary of State has certified in writing that the patient is capable of understanding its nature, purpose and likely effects, and has consented to it".

The Mental Health Act simply requires written certification of the patient's understanding of the treatment being offered, and his consent to it.

The explanatory Memorandum to Parts I to VI, VIII and X of the Mental Health Act 1983 states, in paragraphs 196 and 197, that the RMO must use form 38 to certify the patient's consent, including an outline of the plan of treatment which, it is expected, will be "described in detail in the patient's medical records". This does not take us very much further than did the Act itself about what to write on form 38 .

It is in the latest (August 1993) version of the Code of Practice that we find, in paragraph 16.12, the following regarding medication after three months: "If the patient consents, the RMO must certify accordingly (Form 38 ). The RMO should indicate on the certificate the drugs proposed by the classes described in the British
National Formulary (BNF), the methods of their administration, and the dose range indicating the dosages if they are above BNF advisory maximum limits".

Thus, while we are required to describe in detail in the patient's medical records the treatment plan to which the patient has consented, we are only expected to indicate on form 38 an outline of the treatment plan, the BNF classes of the drugs to which the patient has consented, and the dose range. We are expected to write in specific dosages only if we intend to exceed BNF maximum dosages.

I hope that consultant psychiatrists, in their capacity as RMOs, and Mental Health Act Commissioners alike, will be aware that there is no requirement in the law of the land for RMOs to name any psychotropic drugs on form 38 , to specify dosages (unless exceeding BNF maximum limits), or to write only one drug of any one BNF class. Some Commissioners have taken issue with RMOs for prescribing more than one type of medication of a given class for their patients. Were we to follow this advice, there would be no place for such very useful combinations as lithium carbonate and carbamazepine, or combinations of antidepressive drugs.

AzUONYE, I. O. Adult Mental Health Unit, Lambeth Healthcare NHS Trust, 108 Landor Road, Stockwell, London SW9 9NT

\section{Absolute power of discharge}

Sir: A recent Mental Health Act Commission visit to our hospital questioned the short period of detention to which some of our patients were subjected while under Section 3 . In reviewing these cases, we have discovered that the termination of the Section was determined by the deaths of the patients.

This appears to highlight a deficiency in the 1983 Mental Health Act, not previously discussed-namely that an absolute power of discharge of patients detained under the Act rests with God.

P. Divall and M. Jelley, Consultants in Old Age Psychiatry. Department of Psychiatry of Old Age, St. Martin's Hospital, Bath BAZ 5RP 